\title{
A IMPORTÂNCIA DA EDUCAC̄̃̃O PERMANENTE COMO ESTRATÉGIA PARA QUALIFICAR O PROCESSO DE COLETA DE SANGUE DO DOADOR PROMOVENDO A SEGURANÇA NA TERAPIA TRANSFUSIONAL
}

A transfusão de sangue jamais será um procedimento isento de riscos. Milhares de bolsas de sangue são coletadas anualmente no Brasil, exigindo serviços de hemoterapia bem estruturados, com recursos humanos qualificados e sistema de gestão de qualidade implementados. Define-se como ciclo do sangue o processo sistemático destinado à produção de hemocomponentes, que abrange as etapas de captação, triagem clínica, coleta, triagem laboratorial, processamento, armazenamento, transporte e distribuição. A resolução COFEN 511/2016 descreve que compete ao enfermeiro dos serviços de hemoterapia estabelecer ações de treinamento operacional. Nesse contexto, a fim de promover a qualidade e segurança transfusional, foi implementado o processo de educação permanente na área de coleta do hemocentro.

\section{Metodologia:}

Os treinamentos são realizados nas admissões dos novos colaboradores e/ou de acordo com a análise e monitoramento dos indicadores de qualidade e desempenho individual baseados nos relatórios gerados pelo sistema de gestão informatizado, como: índice de rejeição clínica na triagem, descarte por excesso ou baixo volume, descarte por manuseio inadequado do sistema de coleta, presença de coágulos na bolsa de sangue total, hemólise e/ou contaminação.

\section{Resultados}

Com o objetivo principal de prestar uma assistência qualificada aos doadores de sangue, desde Setembro/2017, após a constituição/designação de uma equipe de educação permanente composta por 2 enfermeiros, alinhados com as recomendações das legislações vigentes, foi possível sistematizar os processos de trabalho na área de suporte técnico do HEMOCENTRO/UNICAMP, atualmente composta por uma equipe de 13 enfermeiros e 36 técnicos de enfermagem, conforme estabelecem os protocolos institucionais, garantindo eficiência nos treinamentos do profissionais recém admitidos, padronização das ações executadas pelos profissionais na unidade, além de implementar ações de treinamento operacional baseados em indicadores individuais, de modo a promover capacitação e atualização contínua dos Enfermeiros e Técnicos de Enfermagem, assegurando a qualidade dos procedimentos realizados na unidade, impactando diretamente na segurança da terapia transfusional.

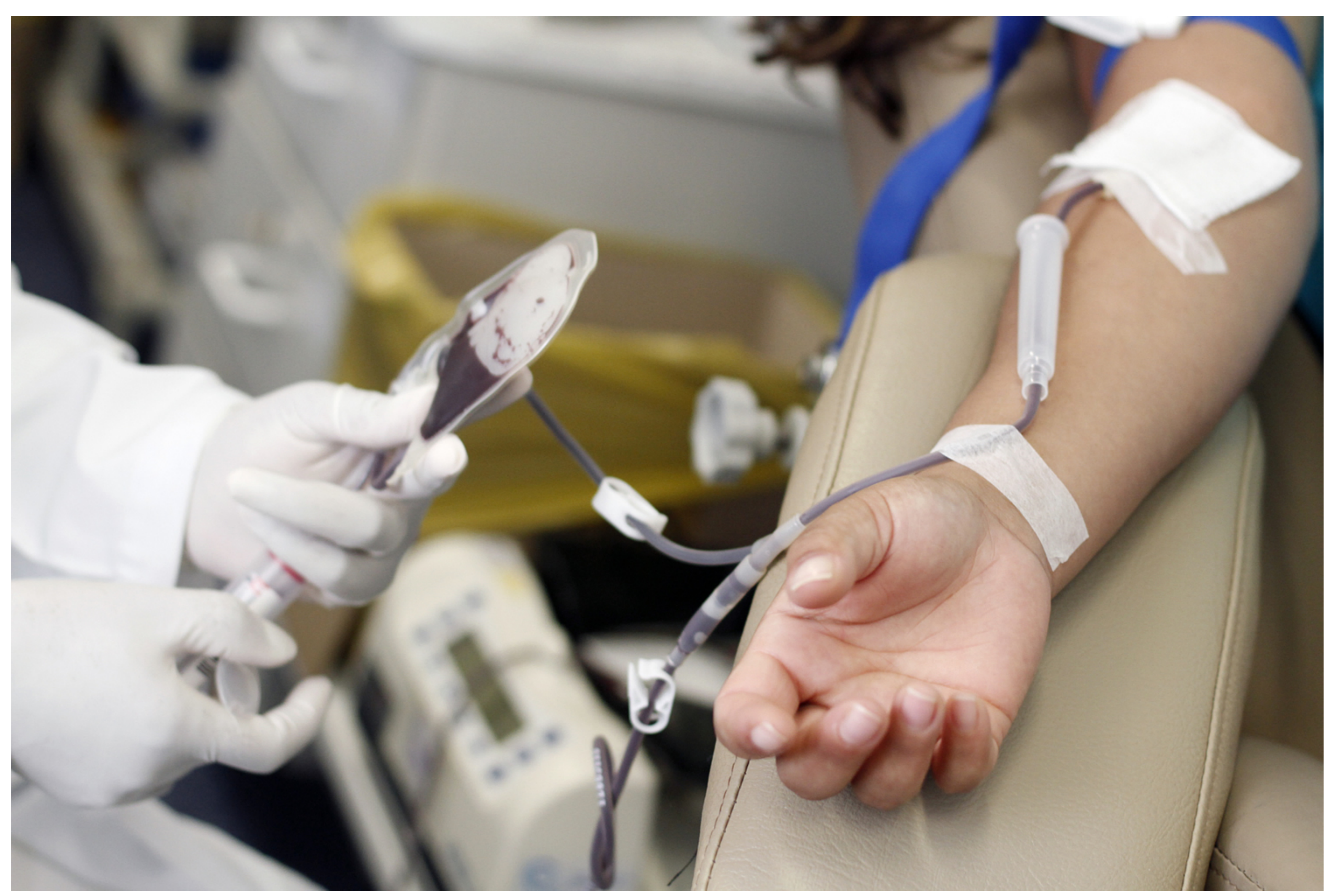

Legenda: Imagens do Google, Direitos autorais: carlospoly@yahoo.com.br

\section{Considerações finais:}

A estratégia de implementação de uma equipe de educação permanente na área de coleta do HEMOCENTRO/UNICAMP possibilitou organizar e sistematizar as ações da equipe que presta assistência aos doadores de sangue, além de proporcionar segurança das práticas assistenciais e autonomia para a equipe de enfermagem que atua na unidade.

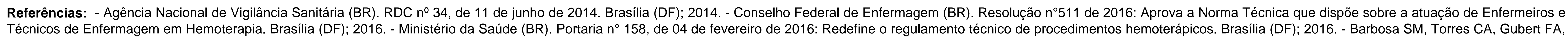
Pinheiro PNC, Vieira NFC. Enfermagem e a prática hemoterápica no brasil: revisão integrativa. Acta Paulista de Enfermagem. 2011; 24(1):132-6.

Sínteses: Rev. Eletrôn. SIMTEC, n. 7, e019035, set. 2019 - ISSN 2525-5398 